\title{
Aplikativne možnosti geografije pri preučevanju pobočnih procesov
}

\author{
Blaž Komac \\ Geografski inštitut Antona Melika, Znanstvenoraziskovalni center SAZU, \\ Gosposka 13, 1000 Ljubljana, Slovenija \\ e-mail: blaz.komac@zrc-sazu.si
}

\section{Matija Zorn}

Geografski inštitut Antona Melika, Znanstvenoraziskovalni center SAZU, Gosposka 13, 1000 Ljubljana, Slovenija

e-mail: matija.zorn@zrc-sazu.si

\section{Izvleček}

Objavljamo pregled slovenske geografske literature o pobočnih procesih, pišemo o geografskih metodah preučevanja pobočnih procesov in predlagamo uporabo "terenskega obrazca za opis gmotnega odnašanja 1.0". Z obrazcem pridobimo okrog 120 podatkov, ki nam pomagajo pri poenotenju in kvantifikaciji geografskega preučevanja pobočnih procesov.

Ključne besede: aplikacija geografije, metodologija terenskega dela, pobočni procesi, gmotno odnašanje, terenski obrazec

\section{Application Possibilities of Geography Concerning Slope Processes Research}

\begin{abstract}
The article brings a review of up to date Slovene geographical literature on slope processes, discusses the geographical methods of slope processes research and proposes the use of the "field-work record sheet for mass wasting research 1.0". By the record sheet it is possible to acquire about 120 data that will help us unify and quantify the geographical slope processes research.
\end{abstract}

Key words: application of geography, field-work methodology, slope processes, mass wasting, field-work record sheet 


\section{UVOD}

V vzpetem svetu so pobočni procesi pomemben del geomorfnih procesov. So posledica fizikalne zakonitosti, da gravitacija sili delce iz nestabilnih višjih leg v nižje lege. Pri premeščanju gradiva se potencialna energija sprosti hipoma (podori) ali pa gre za daljši proces (počasen plaz), teoretično (po Davisu 1899) se sprošča, dokler vse gradivo ne doseže erozijske baze.

Človek je v preteklosti potencialno nevarna območja uporabljal za ekstenzivne dejavnosti, naselja pa so stala na "varnih" območjih. Znanje o nevarnostih narave se je prenašalo iz roda $\mathrm{v}$ rod, katastrofalne dogodke je sprejemal kot usodo oziroma voljo Boga. V iskanju ravnotežja med varnostjo naselij in pogostostjo naravnih nesreč ter s preventivo je uspel znižati možnost škode na minimum (Fuchs in ostali 2001, 9).

Na koncu 19. in v 20. stoletju se je v Alpah povečeval naselbinski in turistični pritisk. $Z$ individualizacijo družbe in rahljanjem tradicionalne družinske strukture se je spremenil odnos do narave, znanje o pobočnih procesih, ki so ga pridobile generacije, pa se je izgubilo. Namesto da bi se človek izogibal potencialno nevarnim območjem, je začel posegati vanje, misleč, da je s tehničnimi sredstvi mogoče preprečiti uničenje zgrajenega. Povečal se je obseg škode zaradi naravnih nesreč (Fuchs in ostali 2001, 9).

Razmišljanje na dolgi rok je človeku, ki živi le nekaj desetletij, tuje, naravni procesi pa so dolgotrajni. Zato je pomembno znanje geomorfologov, ki lahko na podlagi znamenj o preteklih in recentnih procesih $\mathrm{v}$ naravi (glej preglednico 1) sklepajo na možne dogodke v prihodnosti. Znova prihajamo do spoznanja, da je preventiva boljša kot odstranjevanje posledic. Narave ne moremo obvladati, zato moramo premišljeno posegati vanjo. Pri osveščanju imamo pomembno vlogo geografi, ki združujemo znanje o geomorfnih procesih z družbenogeografskimi vsebinami.

Preglednica 1: Znamenja preteklih in recentnih pobočnih procesov (prirejeno po Chorley in ostali 1984, 579-580).

\begin{tabular}{|l|l|}
\hline opazovane reliefne in druge oblike & $\begin{array}{l}\text { možen način premikanja gradiva } \\
\text { ali vrsta pobočnega procesa }\end{array}$ \\
\hline $\begin{array}{l}\text { spremembe zgodovinskih (arheoloških) } \\
\text { nivojev }\end{array}$ & polzenje \\
\hline $\begin{array}{l}\text { povečana potreba po vzdrževanju cest, } \\
\text { napeljav, poslopij }\end{array}$ & plazenje ali drugi procesi, odvisno od primera \\
\hline prestavitev cest, ograj in podobnih objektov & plazenje ali drugi procesi, odvisno od primera \\
\hline zaledne razpoke vzporedne s pobočjem & plazenje \\
\hline
\end{tabular}


Aplikativne možnosti geografije pri preučevanju pobočnih procesov

\begin{tabular}{|l|l|}
\hline $\begin{array}{l}\text { zviti vertikalni objekti ("pijana drevesa", } \\
\text { daljnovodi...) }\end{array}$ & polzenje \\
\hline odprte razpoke v trdni kamnini & $\begin{array}{l}\text { delovanje vode, ledu ali preperevanja, možen } \\
\text { nastanek podora }\end{array}$ \\
\hline stopnjasto pobočje & plazenje \\
\hline $\begin{array}{l}\text { nenadne spremembe rastja prečno na } \\
\text { pobočje }\end{array}$ & starejše plazenje \\
\hline grbinasto pobočje & polzenje \\
\hline vzdolžni deli pobočij brez rastja & različni pobočni procesi, odvisno od primera \\
\hline $\begin{array}{l}\text { mlado rastje oziroma rastje iste starosti } \\
\text { na pobočju }\end{array}$ & $\begin{array}{l}\text { posledica zadnjega večjega } \\
\text { procesa, odvisno od primera }\end{array}$ \\
\hline "sveža" kamnina na pobočju & podor, kamniti zdrs \\
\hline pronicanje na strmem pobočju & visoka podtalnica \\
\hline $\begin{array}{l}\text { močvirno območje na pobočju ali } \\
\text { njegovem vznožju }\end{array}$ & visoka podtalnica, slabo odtekanje vode \\
\hline neobičajne prekinitve površinskega odtoka & vodni tokovi v preperini (piping) \\
\hline
\end{tabular}

\section{PREGLED POMEMBNEJŠE SLOVENSKE GEOGRAFSKE LITERATURE O POBOČNIH PROCESIH}

Pregled literature o pobočnih procesih zajema dostopna slovenska geografska dela o usadih, zemeljskih plazovih (v nadaljevanju: plazovih), podorih in tokovih, ne obravnava pa geomorfne vloge snežnih plazov, pobočnih procesov $\mathrm{v}$ ožjem smislu (erozija, denudacija) in kvartarnega razvoja površja pri nas. Izognili smo se navajanju virov, ki so delo drugih strok, čeprav mnogi prinašajo tudi za geografe zanimive vsebine. Prispevke smo razvrstili kronološko in v tematske sklope.

Med prvimi velja omeniti delo Seidla (1919) o plazu pri Zagorju, Planine $(1951,1952)$ o pobočnih procesih in podoru na Javorščku, Melika s sodelavci (1954) o usadih na Celjskem in Šifrerja $(1955,1960)$ o pleistocenskem razvoju dolin Tolminke in Zalašce ter o učinkih neurja na območju med Konjicami in Krškim. Ilešič (1956) je pisal o dobraških podorih. Gams (1959) je opisal pojave polzenja zemlje in usade na Goričkem ter njihov vpliv na razvoj površja. Kert (1959) je opisal zemeljske plazove v Slovenskih goricah, Melik (1961, 1962) pa geomorfno vlogo podorov pri oblikovanju reliefa $v$ Zgornjem Posočju. Šifrer $(1962,164)$ je poročal o posledicah neurja med Peco in Zgornjo Pako in omenja plaz iz rudniške jalovine. Sore $(1963,1970)$ je pisal o plazovih na Sotelskem in Celjskem, Meze (1963) pa o pomenu usadov in pla- 
zov pri oblikovanju površja v terciarnih kamninah Voglanjsko-Sotelske Slovenije. Radinja (1971, 1974, 1983b) je pisal o usadih v Vipavski dolini, na Sotelskem in v subpanonski Sloveniji. Študentje geografije so poročali o pojavu kamnitega plazu v dolini Kamniške Bistrice (Slušatelji 1971). Šifrer (1981) je opisal posledice ujme v severovzhodni Sloveniji leta 1980, kjer so nastali številni usadi in plazovi. Orožen Adamič je pisal o plazu v Zagorju (1988) in poročal o podoru v Trenti (1990). K. Natek (1989, 1990a, 1990b) je opisal geomorfno vlogo usadov $\mathrm{v}$ Voglanjskem gričevju, opredelil morfometrične značilnosti in tipologijo usadov $\mathrm{v}$ Halozah ter preučil usade $\mathrm{v}$ terciarnem gričevju vzhodne Slovenije. Gabrovec in Brečkova (1990) sta opisala usade v dolini Lahomnice, ki so nastali leta 1989.

Orožen Adamič je skupaj z Vidicem (1991) opisal razmere po ujmi leta 1990 v Škofjeloškem hribovju, Repolusk (1991) takratne dogodke v dolini Kamniške Bistrice, Meze (1991) pa njene posledice v Zgornji Savinjski dolini. K. Natek (1991) je opisal plazove v Zgornji Savinjski dolini, Kladnik (1991) pa takratne razmere v Podvolovljeku, kjer je plaz ustvaril zajezitveno jezero. M. Natek (1991) je opisal plazove in usade v Celjski kotlini, Gams (1991a) razmere v Mislinjski in Mežiški dolini. Razmere v severovzhodni Sloveniji je opisal Žiberna (1991).

O plazovih v Zasavju leta 1991 je pisala Drnovškova (1992), o takratnih razmerah v severovzhodni Sloveniji pa Žiberna (1992). M. Natek (1992) je pisal o stanju plazov v Zgornji Savinjski dolini leto dni po zgoraj omenjeni ujmi. Šifrarjeva (1992) je opisala usade med Kladjem in Cerknim, Kraljeva (1993) pa plazove v občini Zagorje. Maher in Pavšek (1992) sta predstavila podorno ogroženost alpskega sveta in vpliv človeka na podore. Pavšek (1994a, 1994b, 1996) je opisal skalni podor v Trenti, plaz pod Krnom in podor na Mangartu, ki ga je preučil tudi skupaj s Hrvatinom (1995). O pobočnih procesih v Posočju je poročal še Rojšek $(1991,1995)$. O plazovih, ki so nastali v porečju Bolske leta 1994 je pisal M. Natek (1995). Golob in Hrvatin (1996) sta opisala značilnosti podorov v slovenskih gorah. O meliščih, ki so neposredna posledica intenzivnih pobočnih procesov, sta pisala Kladnik $(1980,1981)$ in Gams (1991b). Orožen Adamič (1998) je prispeval besedilo o usadih v monografiji o Sloveniji. Golob (1998) je priobčil prispevek o podorih v ljudskem izročilu. Komac (2001a, 2001b, 2001c) je pisal o drobirskem toku v Logu pod Mangartom, skupaj z Zornom (2002a, 2002b) pa sta pisala o plazu nad Kosečem in recentnih pobočnih procesih $v$ Zgornjem Posočju. Zorn in Komac (2002) sta pisala o pobočnih procesih in drobirskem toku v Logu pod Mangartom. Zorn (2001, 2002a, 2002b) je podrobno obdelal podore v slovenskih in zamejskih Alpah, Pečnikova (2002) pa plazove v Zgornji Savinjski dolini.

Raznolikost procesov, veliko število avtorjev, pestrost slovenskih narečij in drugačna poimenovanja istih procesov $\mathrm{v}$ drugih strokah, so geografe neneh- 
no silili $\mathrm{k}$ večji enotnosti in oblikovanju terminologije. Med pomembnejšimi tovrstnimi prispevki je delo Radinje (1971), ki razpravlja o usadih, Gamsa (1956) o zemljepisnem izrazju s poudarkom na usadu, podoru, kamnitem plazu, soliflukciji in kraškem udoru in deli istega avtorja (1989a, 1989b), kjer je predstavil terminologijo premikanja zemeljskih gmot $\mathrm{z}$ razlago zemeljskega in kamnitega plazu, toka, kamnitega toka, podora, kraškega udora, ugreza, ugreznine, pogreznice, usada in polzenja. Leta 2001 je Gams predstavil še plazovno terminologijo na primeru drobirskega toka $\mathrm{v}$ Logu pod Mangartom. Kunaver $(1995,21 ; 2000,101)$ je prispeval definicijo podora in usada, K. Natek (1996) pa opis plazov in usadov. Zorn (2001) je opredelil izrazje pobočnih procesov s poudarkom na podorih, ki sta ga dodelala Zorn in Komac (2002). Kladnik (Geografija 2001) je prevedel in priredil geografski leksikon, ki podrobno obravnava tudi pobočne procese. $V$ širšem smislu velja omeniti delo Badjure (1953) in številne geografske učbenike (na primer Belec 1983, Kunaver in ostali 1997, Natek in ostali 2000) ter atlase (na primer Heritage in ostali 2001).

Gams (1983b) je objavil prispevek o naravnih nesrečah z vidika celovitega geografskega pristopa. Bogato geografsko znanje je bilo uporabljeno za preučevanje ogroženosti visokogorskih dolin s strani podorov, kamnitih tokov, hudournikov, melišč in snežnih plazov na primeru doline Kamniške Bistrice (Gams in Bat 1983). Pavšek (1992) je na primeru dolin Kot in Vrata v Julijskih Alpah predstavil študijo ogroženosti zaradi naravnih nesreč, Perko (1990) je s tega vidika preučil ogroženost Krške kotline. Fridlova in ostali (1996) so v študiji z uporabo geografskega informacijskega sistema preučili odvisnost naravnih nesreč od tipov pokrajin oziroma pokrajinskih sestavin. Gabrovec (1990) in Perko (1992a) sta preučila možnosti uporabe digitalnega modela reliefa pri preučevanju usadov. Plut in ostali (1978) so na primeru doline Koritnice predstavili vrednotenje alpskega sveta. Radinja (1983a) je predstavil sintezni pregled geografskih del o naravnih nesrečah, K. Natek (1996) pa analizo ogroženosti površja Haloz in regeneracijske sposobnosti površja po katastrofalnem neurju.

Gabrovec in Hrvatin (1998) sta na ozemlju Slovenije predstavila tipologijo reliefa in opredelila najznačilnejše pobočne procese. Sistematičen pregled pobočnih procesov s poudarkom na podorih oziroma plazovih prinašata deli Zorna (2001) in Pečnikove (2002). Nekatera dela pobočne procese obravnavajo z vidika njihovega vpliva na človeka (Gams 1983a, 1983b) ali podajajo celovit pregled dotedanjih raziskav (Radinja 1983b). Številna geografska dela pobočne procese omenjajo kot del širšega geomorfnega dogajanja ali v povezavi z drugimi procesi (na primer Planina 1951, Melik 1954, Kunaver 1975, Natek K. 1985, Perko in Orožen Adamič 1998). Leta 2002 je izšla monografi- 
ja o naravnih in drugih nesrečah in varstvu pred njimi, ki med naravnimi nesrečami obravnava tudi pobočne procese (Ušeničnik 2002).

Številna poglobljena dela in terminološki prispevki kažejo na nenehen razvoj in poglabljanje geografske misli. Geografsko znanje o pobočnih procesih je razpršeno, raziskovanje je bilo v nekaterih obdobjih odvisno od posameznikov. Razmeroma slabo je zastopana kvantifikacija, kar je posledica slabe opremljenosti z merilnimi napravami in laboratorijsko opremo, pa tudi časa in denarja, ki ga namenjamo raziskavam. Posledica tega je dejstvo, da ostane geografsko raziskovanje pobočnih procesov pogosto neopaženo, geografsko znanje in geografske metode pa zaradi nepoznavanja niso cenjene.

\section{METODOLOGIJA TERENSKEGA PREUČEVANJA POBOČNIH PROCESOV}

\subsection{Pred terenskim preučevanjem pobočnih procesov}

Preden se odpravimo na teren moramo pregledati dostopno literaturo in geografske podlage. Pregledati je potrebno geomorfološke in geološke raziskave ter dela o podnebju, vodah, rastju in prsti. Pomembne so geološke karte v merilu 1:100.000 $\mathrm{s}$ tolmači, mnogo uporabnejše rokopisne geološke karte v merilu 1:25.000 žal še vedno niso dostopne. Priročna podlaga so temeljni topografski načrti oziroma digitalni orto foto načrt v merilu 1:5000 in 1: 10.000. Za pojave večjega obsega so uporabne topografske karte v merilu 1: 25.000. Zanimivi sta pedološka karta in karta rabe zemljišč (Natek 1996, Petek 2001).

$\mathrm{V}$ novejšem času pogosto uporabljamo stometrski in petindvajsetmetrski digitalni model višin ter različne metode daljinskega zaznavanja (Fridl in ostali 1996, Gabrovec 1990, Perko 1992a, Perko 2001, Oštir in ostali 2000, Oštir in ostali 2002). Pomembne so karte reliefa in naklonov (Perko 1992b, 1998, 2001), pomagamo si s podatki iz zemljiškega katastra in ostalimi zgodovinskimi viri (na primer Rajšp 1995-2001), med katerimi so najpomembnejši viri "prve roke", ki izpričujejo neposreden stik avtorja z dogodkom. Pogosteje pa pri iskanju podatkov naletimo na vire "druge roke", kjer avtor navaja dejstva, ki jih je povzel po starejšem viru. Te najdemo na primer v popotnih dnevnikih ali starejših zgodovinah nekega območja (Grafenauer 1960, 249-268). Za geomorfne procese nastale $\mathrm{v}$ zadnjih dvesto letih so pomemben vir časniki, na preteklo geomorfno dogajanje nas opozarjajo še lokalne pripovedke in pesmi, kot tudi krajevna in ledinska imena. Tudi $\mathrm{v}$ drugih delih najdemo napotke o tem, na kaj je treba biti pri raziskavah pozoren (na primer Gams in Bat 1983, Pavšek 1992). V pomoč so nam objave drugih strok ali elaborati in drugi težko 
dostopni viri. Ob študiju gradiva si je smiselno zapisati misli in jih $\mathrm{v}$ strnjeni obliki uporabiti pri terenskem preučevanju. Priprava na terensko delo je temeljnega pomena za terensko raziskovanje - čim boljša je, tem hitrejše in temeljitejše bo terensko delo (Kern 1988, 2).

\subsection{Terensko preučevanje pobočnih procesov}

Pred odhodom na teren dobro premislimo, da s seboj ne vzamemo vse možne opreme, temveč le tisto, ki jo bomo uporabljali. Pomembne so karte, kompas, geološki kompas, globalni pozicijski sistem (GPS), po možnosti kladivo. Prav pride merilni trak (20-30 m), za merjenje težko dostopnih predelov laserski merilec razdalj, smiselno je uporabljati naklonomer in višinomer. Potrebujemo terenski zvezek, svinčnik z radirko in šilčkom, barvnike, geotrikotnik, vodoodporni flomaster, vrečke za vzorce, fotoaparat $\mathrm{z}$ zoomom in dovolj filmi oziroma prostora $\mathrm{v}$ spominskem modulu, daljnogled, nahrbtnik, po možnosti lopato. Ne pozabimo še na lastno varnost in vzemimo s seboj vsaj rokavice in čelado (podori) ter primerno obutev in obleko. Redko uporabljamo vrtalne naprave ali georadar, ki so potrebni za ugotavljanje sestave tal ali globine premikajoče se gmote.

Pred obiskom terena se pri oblasteh pozanimamo, ali je območje dostopno in v primeru zapore pridobimo dovoljenje. Pri domačinih se pozanimamo o dotedanjem poteku pobočnega procesa, njegovih posledicah in o znamenjih $\mathrm{v}$ pokrajini, ki so morebiti že prej kazala nanj. Na ta način pridobljene podatke kasneje preverimo pri drugih osebah.

Kot zahteva deduktivni pristop (Vrišer 2002, 102), skušamo na terenu najprej pridobiti širši pregled nad razmerami in se nato podamo k pobočnemu procesu. Če je mogoče, procese preučujemo in opisujemo od zgoraj navzdol, kot so se dejansko zgodili.

Pojav najprej poimenujemo in opredelimo način premikanja gradiva. Nato se lotimo meritev (glej prilogi k članku). Območje fotografiramo in skiciramo (dobro si je zapomniti in kasneje na skici ali fotografiji označiti stojišče). Skice morajo biti čim preglednejše, vsebujejo naj skupno legendo, merilo in oznako smeri neba.

Območje podrobno geomorfološko (Gams in Natek 1981, Natek 1983, Bognar in ostali 1985) in geološko kartiramo (Ribičič 2002). Važno je opisati vsaj glavne poteze reliefa v okolici. Kartiramo in preučimo tudi rabo zemljišč (Petek 2001) ter antropogene sestavine na območju pobočnega procesa. Na terenu vzamemo vzorce kamnine, premaknjenega gradiva in vode. Izmerimo temperaturo, pretok vode, trdoto in vsebnost suspendiranega gradiva. Po opravljenem terenskem delu povzamemo najpomembnejša dognanja. 
Slika 1: Nekatere vrste pobočnih procesov v odvisnosti od vlažnosti in hitrosti premikanja (prirejeno po Chorley in ostali 1984, 235).

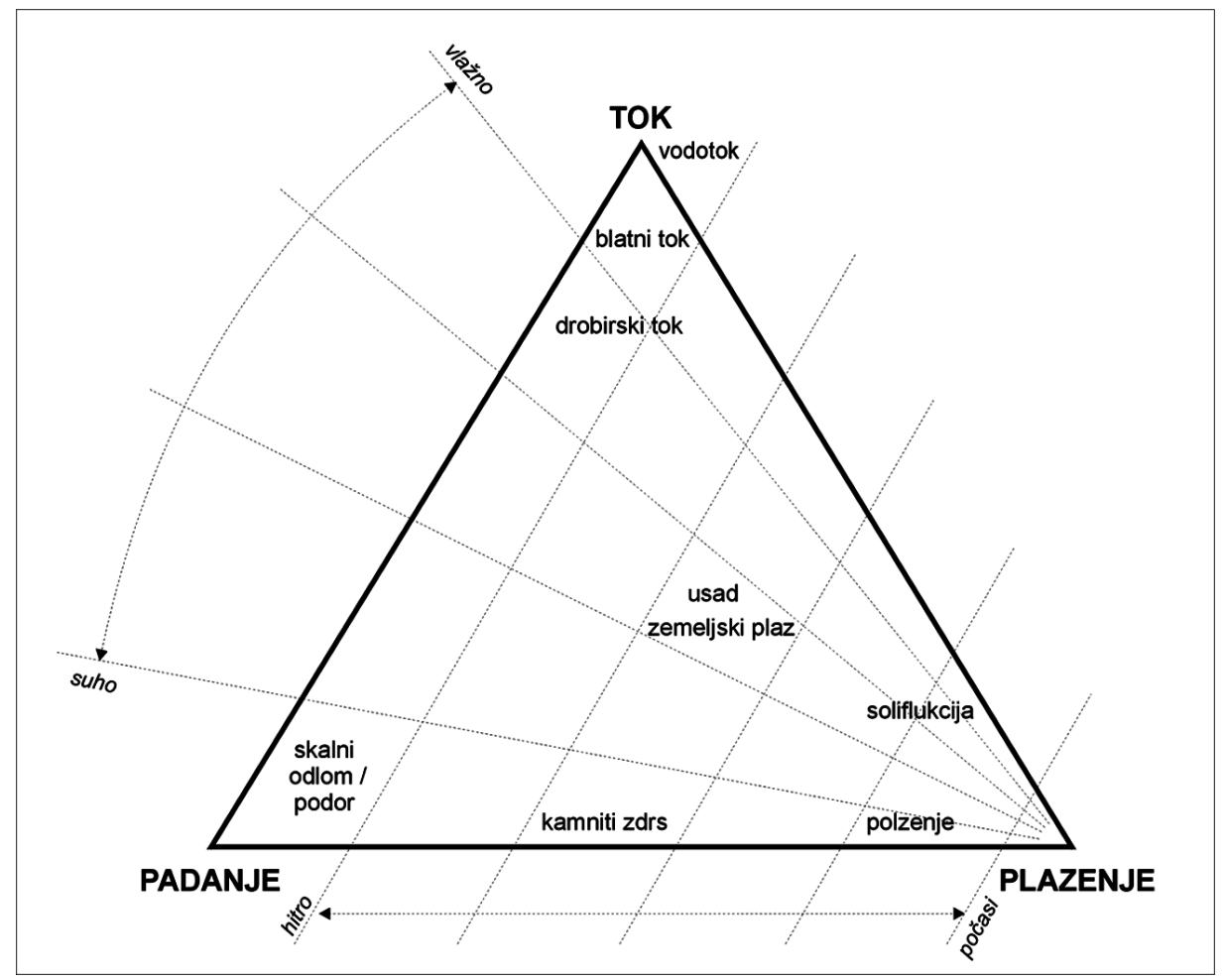

Uporaben pripomoček pri preučevanju je tudi terenski obrazec, ki je v prilogi. Podatke vpisujemo v prazna polja ali pa obkrožimo vnaprej določene odgovore. Glede na način premikanja gradiva ločimo tok (na primer drobirski tok), plazenje (na primer zemeljski plaz) in padanje (na primer podor). Za poimenovanje tovrstnih procesov se $\mathrm{v}$ tuji literaturi uporablja angleški izraz mass wasting, ki ga nekateri v slovenščino prevajajo kot "masovno odnašanje" (Mikoš 2000, 109). Zaradi pomensko spornega izraza "masovno" predlagamo ustreznejši izraz "gmotno odnašanje", ki pomeni odstranjevanje gmote z delovanjem geomorfnih procesov na pobočjih. Izraz opisuje omenjene geomorfne procese na pobočjih, ne pa erozije in denudacije v ožjem smislu besed. "Terenski obrazec za opis gmotnega odnašanja 1.0" (priloga 1 in priloga 2) predlagamo v uporabo v geografskem terenskem preučevanju.

Namen obrazca je olajšati raziskovalno delo in opozoriti na pomembne vidike terenskega preučevanja. $Z$ njim pridobimo okrog 120 podatkov, ki nam 
pomagajo pri poenotenju in kvantifikaciji geografskega preučevanja, kar omogoča lažjo primerjavo. Obrazec je prvi korak k učinkovitejšemu preučevanju pobočnih procesov, zato tudi oznaka 1.0. Nastal je na podlagi virov, literature (Chorley in ostali 1984, Kern 1988, Ribičič in ostali 1994, Waltham 1994, Hrvatin in Gabrovec 1998, Verbič 1998, Mirtič in ostali 1999, Pavšek 2000, Horvat 2001, Petek 2001, Zorn 2001, Pečnik 2002, Zorn 2002b, Zorn in Komac 2002, Ribičič 2002) in spoznanj avtorjev.

\section{SKLEP}

Če geografi ne bomo preučevali pobočnih procesov, bo manjkal naš vidik, ki lahko deluje povezovalno tudi med drugimi strokami. Od njih se lahko naučimo natančnosti, "da geografija ne bo le površna veda o površju", in rednejše uporabe laboratorijskih, fizikalnih, kemičnih, matematičnih in drugih metod.

Postavlja se vprašanje, kje je danes mesto geografije pri preučevanju pobočnih procesov? Geografi so sicer sodelovali pri oblikovanju Nacionalnega programa varstva pred naravnimi in drugimi nesrečami (2002), v izdelavo tistega dela, ki govori o pobočnih procesih pa niso bili vključeni.

Geologi so že vzpostavili računalniško voden (s programom GIS $\left.S D M S^{\prime} 97\right)$ kataster plazov in na ta način evidentirali več sto plazov (Vzpostavitev 2002). Naša želja je zbrati podatke o čim več pobočnih procesih na Slovenskem in vzpostaviti geografski informacijski sistem, ki bi omogočal dostop do podatkov, njihov prikaz in analizo. V Avstriji so leta $1975 \mathrm{z}$ zakonom o gozdovih (Forstgesetz 1975) in leta 1976 s posebno odredbo (Verordnung 1976) določili izdelavo načrtov ogroženosti državnega ozemlja na "hudourniških in plazovitih območjih". Do leta 1994 je bilo izdelanih 865 takšnih načrtov, na katerih so zbrani podatki o 10.000 hudournikih in 5000 plazovih. Dokument je javno dostopen in ga morajo uporabljati pri prostorskem načrtovanju ter graditvi objektov (Mikoš 1997, 3). Tudi Slovenija bi se morala lotiti sistematičnega evidentiranja območij, kjer pobočni procesi ogrožajo človeka. Obstajata že kataster zemeljskih (Ribičič in ostali 1994) in snežnih plazov (Horvat 2001, 137), ki pa nista povezana niti javno dostopna, izdelana pa je že tudi karta ogroženosti območja mestne občine Nova Gorica. Pri evidentiranju območij, ki jih ogrožajo pobočni procesi, bi predlagani terenski obrazec lahko bil v pomoč, geografi pa bi združili znanje geomorfologije in prostorskega planiranja.

Prihaja čas, da spet razmislimo o dejstvu, da človek ne more, ne sme posegati v območja, kjer obstaja nevarnost "uničujočih" pobočnih procesov. Če človek tam že prebiva ali deluje, je potreben premišljen, odgovoren pristop in tvorno sodelovanje prebivalcev, strokovnjakov ter predstavnikov državnih in 
lokalnih oblasti. Smisel preučevanja pobočnih procesov je predvsem v njihovem natančnem (s)poznavanju. Znanje omogoča razpoznavanje potencialno ogroženih območij $\mathrm{v}$ pokrajini in dolgoročno usmerjanje poselitve ter drugih človekovih dejavnosti na varnejša območja. Prav zato je nujno sodelovanje strok, ki je marsikje šele v povojih. Terminološke razlike med strokami ne bi smele biti ovira pri komunikaciji, saj je izmenjava znanj neprimerno večjega pomena.

\section{Viri in literatura o pobočnih procesih:}

Badjura, R., 1953. Ljudska geografija - terensko izrazoslovje. Ljubljana, DZS. Belec, B., 1983. Fizična geografija, 1. del. Maribor, Pedagoška akademija, Univerza v Mariboru.

Chorley, R., J., Schumm, S., A., Sugden, D., E., 1984. Geomorphology. London, Methuen.

Davis, W., M., 1899. The Geographical Cycle. Geographical Journal, 14, 481504.

Drnovšek, V., 1992. Zemeljski plazovi novembra 1991 in plazovitost v Zasavju. Ujma, 6, 7-11.

Forstgesetz. Bundesgesetzblatt der Republik Österreich, 440/1975, 3. 7. 1975.

Fridl, J., Gabrovec, M., Hrvatin, M., Orožen Adamič, M., Pavšek, M., Perko, D., 1996. Tipi pokrajin in naravne nesreče. V: Spodnje Podravje s Prlekijo. 17. zborovanje slovenskih geografov, Ptuj, 23.-26. oktobra 1996. Ljubljana, Zveza geografskih društev Slovenije, 132-140.

Fuchs, S., Keiler, M., Zischg, A., 2001. Risikoanalyse: Oberes Suldental, Vinschgau: Kozepze und Methoden zur Erstellung eines Naturgefahrenhinweis-Informationssystems. Innsbrucker Geographische Studien, 31.

Gabrovec, M., 1990. Uporaba digitalnega modela reliefa pri proučevanju usadov na primeru doline Lahomnice. V: 5. znanstveno posvetovanje geomorfologov Jugoslavije, 181-185.

Gabrovec, M., Brečko, V., 1990. Poplave in usadi v dolini Lahomnice. Ujma, $4,16-19$.

Gabrovec, M., Hrvatin, M., 1998. Površje. V: Fridl, J., Kladnik, D., Orožen Adamič, M., Perko, D., (uredniki), 1998. Geografski atlas Slovenije - država v prostoru in času. Ljubljana, DZS, 80-83.

Gams, I., 1956. Zemljepisno izrazje: usad - podor - kameniti plaz - soliflukcija - kraški udor in še kaj. Geografski obzornik, 3, 1, 18-19.

Gams, I., 1959. Geomorfologija in izraba tal v Pomurju. Geografski zbornik, $5,205-251$. 
Gams, I., 1983a. Naravne nesreče v Sloveniji v pregledu. V: Naravne nesreče v Sloveniji kot naša ogroženost. Zbornik posveta, 14. oktober 1983. Ljubljana, Geografski inštitut Antona Melika ZRC SAZU, 10-17.

Gams, I., 1983b. O razsežnosti in potrebnosti raziskovanja naravnih nesreč v Jugoslaviji. V: Naravne nesreče v Jugoslaviji s posebnim ozirom na metodologijo geografskega proučevanja. Zbornik posveta, 13.-15. oktober 1983. Ljubljana, Zveza geografskih društev Slovenije, 5-16.

Gams, I., 1989a. Termini za premikanje zemeljskih gmot. Geografski vestnik $61,171-176$.

Gams, I., 1989b. Terminologija premikanja zemeljskih gmot. Ujma, 3, 122-123.

Gams, I., 1991a. Ujma 1990 v Mislinjski in Mežiški dolini. Ujma, 5, 93-98.

Gams, I., 1991b. Dvojno življenje melišč. Proteus, 53, 8, 299-303.

Gams, I. 2001. Mangartski plaz v luči plazovne terminologije. Ujma, 14-15, 452-453.

Gams, I., Bat, M., 1983. Metodologija kartiranja ogroženosti visokogorskih dolin. V: Naravne nesreče $\mathrm{v}$ Jugoslaviji s posebnim ozirom na metodologijo geografskega proučevanja. Zbornik posveta, 13.-15. oktober 1983. Ljubljana, Zveza geografskih društev Slovenije, 82-93.

Gams, I., Natek, K., 1981. Geomorfološka karta 1: 100000 in razvoj reliefa v Litijski kotlini. Geografski zbornik, 21, 5-67.

Geografija, 2001. Zbirka Tematski leksikoni. Tržič, Učila.

Golob, U., 1998. Podori in ljudsko izročilo. Gea, 8, 4, 74-75.

Golob, U., Hrvatin, M., 1996. Rock 'n' roll v slovenskih Gorah. Grif, 1, 3, 40-43.

Gregorčič, S., 1947. Rabeljsko jezero. Zbrano delo, 1. knjiga. DZS, Ljubljana, $154-158$.

Grafenauer, B., 1960. Struktura in tehnika zgodovinske vede. Ljubljana, Univerzitetna založba.

Heritage, A., Hrvatin, M., Perko, D. (uredniki), 2001. Družinski atlas sveta. Ljubljana, Slovenska knjiga.

Horvat, A., 2001: Metode določanja erozijsko ogroženih območij. Doktorska disertacija. Ljubljana, Biotehniška fakulteta, Oddelek za gozdarstvo in obnovljive gozdne vire.

Hrvatin, M., Pavšek, M., 1995. Podor na Mangartu. Geografski obzornik, 42, $3,10-15$.

Ilešič, S., 1956. Dobrač, podrta gora nad slovensko zemljo. Planinski vestnik, $56,2,56-63$.

Kern, M., 1988. Geologie im Gelände. Stuttgart, Enke.

Kert, B., 1959. Geomorfologija severozahodnih Slovenskih goric. Geografski zbornik, 5, 141-159.

Kladnik, D., 1980. Možnost uporabe poskusnih modelov v fizični geografiji na primeru proučevanja melišč. Geografski vestnik, 52, 155-166. 
Kladnik, D., 1981. Melišča v Kamniško-Savinjskih Alpah. V: Gorenjska: referati in gradivo na 12. zborovanju slovenskih geografov v Kranju in na Bledu od 15. do 17. oktobra 1981. Ljubljana, Geografsko društvo Slovenije, $147-155$.

Kladnik, D., 1991. Ujma 1990 v Podvolovljeku. Ujma, 5, 51-53.

Komac, B., 2001a. Ko se strese zemlja. Grif, 34, 16-19.

Komac, B., 2001b. Ko se strese zemlja. Grif, 35, 45-48.

Komac, B., 2001c. Geografski vidiki nesreče. Ujma, 14-15, 60-66.

Komac, B., Zorn, M. 2002b. Recentni pobočni procesi v Zgornjem Posočju. Geografski obzornik, 49, 1, 10-17.

Komac, B., Zorn, M., 2002a. Poročilo o ogledu plazu nad Kosečem. Ljubljana, Geografski inštitut Antona Melika ZRC SAZU.

Kralj, V., 1993. Zemeljski plazovi jeseni 1992 v zagorski občini. Ujma, 7, 70-72.

Kunaver, J., 1975. Vodnik ekskurzij po Zgornjem Posočju. 10. zborovanje slovenskih geografov - Zgornje Posočje (26.-28. 9. 1975). Ljubljana, Geografsko društvo Slovenije.

Kunaver, J., 1995. Podor. V: Enciklopedija Slovenije. Zvezek 9. Ljubljana, Mladinska knjiga.

Kunaver, J., 2000. Usad. V: Enciklopedija Slovenije. Zvezek 14. Ljubljana, Mladinska knjiga.

Kunaver, J. Drobnjak, B., Klemenčič, M., Lovrenčak, F., Luževič, M., Pak, M., Senegačnik, J., 1997. Obča geografija za 1. letnik srednjih šol. Ljubljana, DZS.

Maher, I., Pavšek, M., 1994. Si bomo podrli gore na glavo? Planinski vestnik, 94, 2, 56-57.

Melik, A., 1954. Slovenija, geografski opis. Slovenski alpski svet. Ljubljana, Slovenska matica.

Melik, A., 1961. Vitranc, Zelenci in Bovško, Geomorfološke študije iz zahodnih Julijskih Alp. Geografski zbornik, 6, 287-332.

Melik, A., Arlič, S., Gams, I., Kolenik, E., Marolt, S., Predan, D., Radinja, M., Rebernik, D., Sore, A., Šifrer, M., Zupančič, Z., Žagar, M., 1954. Povodenj okrog Celja junija 1954. Geografski vestnik, 26, 3-58.

Meze, D., 1963. H geomorfologiji Voglajnske pokrajine in Zgornjega Sotelskega. Geografski zbornik, 8, 77-120.

Meze, D., 1991. Ujma 1990 v Gornji Savinjski dolini, med Lučami in Mozirsko kotlinico. Ujma, 5, 39-50.

Mikoš, M., 1997. Ocena ogroženosti alpskega sveta z naravnimi ujmami. Gradbeni vestnik, 46, 1-3, 2-7.

Mikoš, M., 2000. Izrazje na področju erozijskih pojavov. Gradbeni vestnik, $49,5,102-114$. 
Mirtič, B., Mladenovič, A., Ramovš, A., Senegačnik, A., Vesel, J., Vižintin, N., 1999. Slovenski naravni kamen. Ljubljana, Geološki zavod Slovenije, Zavod za gradbeništvo Slovenije, Oddelek za geologijo NTF.

Nacionalni program varstva pred naravnimi in drugimi nesrečami, Uradni list RS, 44, 21. 5. 2002.

Natek, K., 1983. Metoda izdelave in uporabnost splošne geomorfološke karte. Magistrska naloga, Ljubljana, Filozofska fakulteta, Oddelek za geografijo.

Natek, K., 1985. Geomorfološko dogajanje, čas in mi. Proteus, 8, 4, 301-305.

Natek, K., 1989. Vloga usadov pri geomorfološkem preoblikovanju Voglajnskega gričevja. Geografski zbornik, 29, 37-77.

Natek, K., 1990a. Geomorfološke značilnosti usadov v Halozah. Ujma, 4, 11-15.

Natek, K., 1990b. Usadi v terciarnem gričevju vzhodne Slovenije. V: Geomorfologija in geoekologija. Ljubljana, ZRC SAZU, 67-73.

Natek, K., 1991. Plazovi v Gornji Savinjski dolini. Ujma, 5, 62-65.

Natek, K., 1996. Ogroženost in regeneracijske sposobnosti površja severovzhodne Slovenije na osnovi regeneracije površja v Halozah po katastrofalnem neurju julija 1989. V: Spodnje Podravje s Prlekijo. 17. zborovanje slovenskih geografov, Ptuj, 23.-26. oktobra 1996. Ljubljana, Zveza geografskih društev Slovenije, 141-151.

Natek, K., 2002. Geomorfologija - predavanja v študijskem letu 2000/2001. URL: http://www.ff.uni-lj.si/geo/Pedagosko/gradiva/geomorfologija/geo morfo-predavanja.htm (22. 10. 2002).

Natek, K., Hočevar, M., Vidmar, M., 2000. Geografija, shematski pregledi. Ljubljana, Tehniška založba Slovenije.

Natek, M., 1991. Nekateri geografski vidiki in učinki povodnji v spodnji Savinjski dolini 1. novembra 1990. Ujma, 5, 66-76.

Natek, M., 1992. Odprava posledic povodnji 1. novembra 1990 v Spodnji Savinjski dolini. Ujma, 6, 61-67.

Natek, M., 1995. Poplave v porečju Bolske leta 1994. Ujma, 9, 38-47.

Orožen Adamič, M., 1988. Škoda in odpravljanje posledic zemeljskega plazu v Zagorju. Ujma, 2, 36-37.

Orožen Adamič, M., 1990. Podor v Trenti. Ujma, 4, 38.

Orožen Adamič, M., Vidic, F., 1991. Ujma 1990 v Škofjeloškem hribovju. Ujma, 5, 19-24.

Orožen Adamič, M., 1998. Usadi. V: Perko, D. (ur.), OROŽEN ADAMIČ, Milan (ur.), 1998. Slovenija - pokrajine in ljudje. Ljubljana. Mladinska knjiga.

Oštir, K., Veljanovski, T., Podobnikar, T., Stančič, Z., 2002. Uporaba daljinskega zaznavanja pri opazovanju plazu v Logu pod Mangartom. V: Geografski informacijski sistemi v Sloveniji 2001-2002. Ljubljana, ZRC SAZU, 197-209. 
Oštir, K., Podobnikar, T., Stančič, Z., Mlinar, J., 2000. Digitalni model višin Slovenije InSAR 25. Geodetski vestnik, 44, 4, 374-383.

Pavšek, M., 1992. Ogroženost Triglavskih dolin Kot in Vrata zaradi naravnih nesreč. Ujma, 6, 86-94.

Pavšek, M., 1994a. Skalni podor v Trenti, Ujma, 8, 24-29.

Pavšek, M., 1994b. Zemeljski plaz pod Krnom. Ujma, 8, 30-32.

Pavšek, M., 1996. Skalni podor na Velikem Mangartu. Ujma, 10, 67-69.

Pavšek, M., 2000: Fizičnogeografska pogojenost snežnih plazov v slovenskih Alpah s posebnim ozirom na preventivo. Magistrska naloga. Ljubljana, Filozofska fakulteta, Oddelek za geografijo.

Pečnik, M., 2002. Možnosti nastanka zemeljskih plazov na osnovni geomorfoloških značilnosti površja v Zgornji Savinjski dolini. Diplomsko delo. Ljubljana, Filozofska fakulteta, Oddelek za geografijo.

Perko, D., 1990. Ogroženost vzhodne Krške kotline zaradi naravnih nesreč. Ujma, 4, 91-96.

Perko, D., 1992a. Naravne nesreče in digitalni model reliefa. Ujma. 6, 174-179.

Perko, D., 1992b. Nakloni v Sloveniji in digitalni model reliefa. Geodetski vestnik, 36, 2, 115-121.

Perko, D., 1998. Nakloni površja. V: Fridl, J., Kladnik, D., Perko, D., Geografski atlas Slovenije: država v prostoru in času. Ljubljana, DZS, 86-87.

Perko, D., 2001. Analiza površja Slovenije s stometrskim digitalnim modelom reliefa. Ljubljana, ZRC SAZU.

Perko, D., Orožen Adamič, M., 1998. Slovenija: pokrajine in ljudje. Ljubljana, Mladinska knjiga.

Petek, F., 2001. Vrednotenje rabe zemljišč v slovenskih pokrajinah z vidika kazalcev sonaravnega razvoja. Magistrsko delo, Ljubljana, Filozofska fakulteta, Oddelek za geografijo.

Planina, F., 1951. Podori in usadi. Proteus, 13, 4-5, 144-148.

Planina, F., 1952. Podor na Javorščku. Geografski vestnik, 24, 190-193.

Plut, D., Gosar, A., Klemenčič, M., 1978. Poskus vrednotenja alpskega sveta na primeru doline Koritnice. V: Zgornje Posočje. Zbornik 10. zborovanja slovenskih geografov, Tolmin-Bovec, 26.9.- 28. 9. 1975. Ljubljana, Geografsko društvo Slovenije, 349-365.

Radinja, D., 1971. Usad nad Podrago v Vipavski dolini. Primer porušenega ravnotežja v flišni submediteranski pokrajini. Geog. zbornik, 12, 265-317.

Radinja, D., 1974. Usadi na Sotelskem v pokrajinski luči. Voglanjsko-Sotelska Slovenija. Ljubljana, Geografsko društvo Slovenije, 81-95.

Radinja, D., 1983a. Naravne nesreče v geografski luči. V: Naravne nesreče v Jugoslaviji s posebnim ozirom na metodologijo geografskega proučevanja. Zbornik posveta, 13.-15. oktober 1983. Ljubljana, Zveza geografskih društev Slovenije, 17-29. 
Radinja, D., 1983b. Usadi v subpanonski Sloveniji. V: Naravne nesreče v Sloveniji kot naša ogroženost. Zbornik posveta, 14. oktober 1983. Ljubljana, Geografski inštitut Antona Melika ZRC SAZU, 67-74.

Rajšp, V. (urednik), 1995-2001. Slovenija na vojaškem zemljevidu (17631787; 1804). Zvezek 1-7. ZRC SAZU, Ljubljana.

Repolusk, P., 1991. Učinki poplav 1990 v zgornjem toku Kamniške Bistrice. Ujma, 5, 25-28.

Ribičič, M., 2002. Inženirska geologija. Skripta. Ljubljana, Naravoslovnotehniška fakulteta, Oddelek za geologijo.

Ribičič, M., Buser, I., Hoblaj, R., 1994. Digitalno atributna / tabelarična baza zemeljskih plazov Slovenije za terenski zajem podatkov. V: Prvo slovensko posvetovanje o zemeljskih plazovih, Idrija 17. in 18. november 1994 - Zbornik predavanj. Idrija, Rudnik živega srebra Idrija.

Rojšek, D., 1991. Naravne znamenitosti Posočja. Ljubljana, DZS.

Rojšek, D., 1995. Podor na Mangartu. Proteus, 58, 4, 168-170.

Seidl, F., 1919. Melov plaz pri Zagorju 16. januarja leta 1917. Glasnik muzejskega društva za Slovenijo I, Zvezek 1-4, 33-44.

Slušatelji Oddelka za geografijo FF, 1971. Kamniti plaz s Kokrskega sedla v kot doline Kamniške Bistrice. Proteus, 33, 5, 204-210.

Sore, A., 1963. Zemeljski plazovi na Zgornjem Sotelskem. Geografski zbornik, 8, 121-155.

Sore, A., 1970. Zemeljski plazovi na ozemlju celjske občine. Celjski zbornik, $127-147$.

Šifrar, M., 1992. Usadi med Kladjem in Cerknim. Seminarska naloga. Ljubljana, Filozofska fakulteta, Oddelek za geografijo.

Šifrer, M., 1955. Dolina Tolminke in Zalašce v pleistocenu. Geografski zbornik, 3, 253-298.

Šifrer, M., 1962. Geografski učinki neurja med Peco in Zgornjo Pako. Geografski zbornik, 7, 143-179

Šifrer, M., 1981. Katastrofalni učinki neurij v severovzhodni Sloveniji, avgusta 1980. Geografski zbornik, 21, 157-188.

Šifrer, M., 1988. Kvartarni razvoj Škofjeloškega hribovja. Geografski zbornik, 22, 139-158.

Šifrer, M., Žagar, M., 1960. Geografski učinki neurja med Konjicami in Krškim. Geografski vestnik, 32, 233-246.

Ušeničnik, B. (ur.), 2002. Nesreče in varstvo pred njimi. Ljubljana, Uprava RS za zaščito in reševanje Ministrstva za obrambo.

Verbič, T., 1998. Kamnine. V: Fridl, J., Kladnik, D., Orožen Adamič, M., Perko, D., (uredniki), 1998. Geografski atlas Slovenije, Država v prostoru in času. Ljubljana, DZS, 74-77. 
Verordnung des Bundesministers für Land- und Forstwirtschaft über die Gefahrenzonenpläne. Bundesgesetzblatt der Republik Österreich, 436/1976, 30. 7. 1976.

Vrišer, I., 2002. Uvod v geografijo. Ljubljana, Filozofska fakulteta, Univerza v Ljubljani.

Vzpostavitev računalniško vodenega katastra plazov. URL: http://www.mikrodata.si/Kataster\%20plazov.htm (22. 10. 2002).

Waltham, A., C., 1994. Foundations of Engineering Geology. London, Chapman \& Hall.

Zorn, M. 2001: Gorski relief kot posledica skalnih podorov. Diplomsko delo. Ljubljana, Filozofska fakulteta, Oddelek za geografijo.

Zorn, M., 2002a. Podori na Dobraču. Geografski vestnik, 74, 2.

Zorn, M., 2002b. Rockfalls in Slovene Alps. Geografski zbornik, 42.

Zorn, M., Komac, B., 2002. Pobočni procesi in drobirski tok v Logu pod Mangartom. Geografski vestnik, 74, 1.

Žiberna, I., 1991. Ujma 1990 v severovzhodni Sloveniji. Ujma, 5, 98-101.

Žiberna, I., 1992. Zemeljski plazovi po močnem deževju novembra 1991 v občinah Pesnica, Slovenska Bistrica.

\section{APPLICATION POSSIBILITIES OF GEOGRAPHY CONCERNING SLOPE PROCESSES RESEARCH}

\section{Summary}

Slope processes are an important part of geomorphic processes. They are a consequence of a physical law forcing particles from higher, unstable positions to lower, more stable ones. The release may be instant or lengthy and theoretically, according to Davis, lasts until all the material reaches the base level. Slope processes are repeatedly perceived to be natural disasters, especially when they collide with human activities or interests.

In the past potentially risk areas in the mountains were mainly set aside for extensive activities, while the settlements were located in "safer" areas. Hazards awareness in "dangerous" areas, inherited from one generation to another, allowed the inhabitants to establish a balance between settlement safety and natural disasters. Catastrophic events were taken as a destiny or the will of God. Since the end of the 19th and at the beginning of the 20th century the settling and tourist pressure have risen. The individualization of the society and loosening of the traditional family structure have also changed the relation to nature and the knowledge about the slope processes started disappearing. 
Instead of being avoided, potentially dangerous areas were used in the belief that the slope processes can be entirely regulated by technical means. That is why the extent of the damage due to natural disasters has increased.

We are getting more and more aware that prevention is better than cure. Due to the extensive knowledge of slope processes in connection to human geographical characteristics, geographers have played a crucial role in pointing out the issue.

The article brings the list of the Slovene geographical literature on slope processes. About eighty works have been considered, laying particular stress on landslips, landslides, rockfalls and flows. The literature has been sorted chronologically and thematically, too.

The authors further discuss the geographical methods of slope processes research and propose the use of "field-work record sheet for mass wasting research 1.0". The main aim of this record sheet is to facilitate the slope processes research and to draw attention to its importance. The form contains about 120 data entries. It enables to uniform, quantify and compare the geographical slope processes researches. The instructions to fulfil in the record sheet are also a part of the article.

An important question is where a place of slope processes research is within geography today. Slovene geographers have cooperated in the forming of the National programme for protection from natural and other disasters (2002) but not in the part dealing with slope processes. This document, among other topics, lists slope processes that are dangerous for human life and activities. In the Republic of Slovenia areas endangered by the slope processes should be systematically recorded. The landslides register and avalanches register already exist but their databases have neither been connected nor publicly accessible. The proposed record sheet could therefore be a step forward to a more complex approach helping geographers and others by joining the geomorphologic and common geographical knowledge.

The wisdom of our ancestors should be reconsidered and respected. People should stay away from areas subjected to demolishing slope processes. In case risk areas have already been in use well considered and responsible approach is needed at all levels as well as a dynamic cooperation between local people, experts and authorities as well. Cooperation between different fields of activities is required and terminological differences should not obstruct the communication. The exchange of knowledge must be the highest priority. 
Blaž Komac, Matija Zorn / Dela 18 • 2002 • 171-193

Priloga 1: Terenski obrazec za opis gmotnega odnašanja 1.0

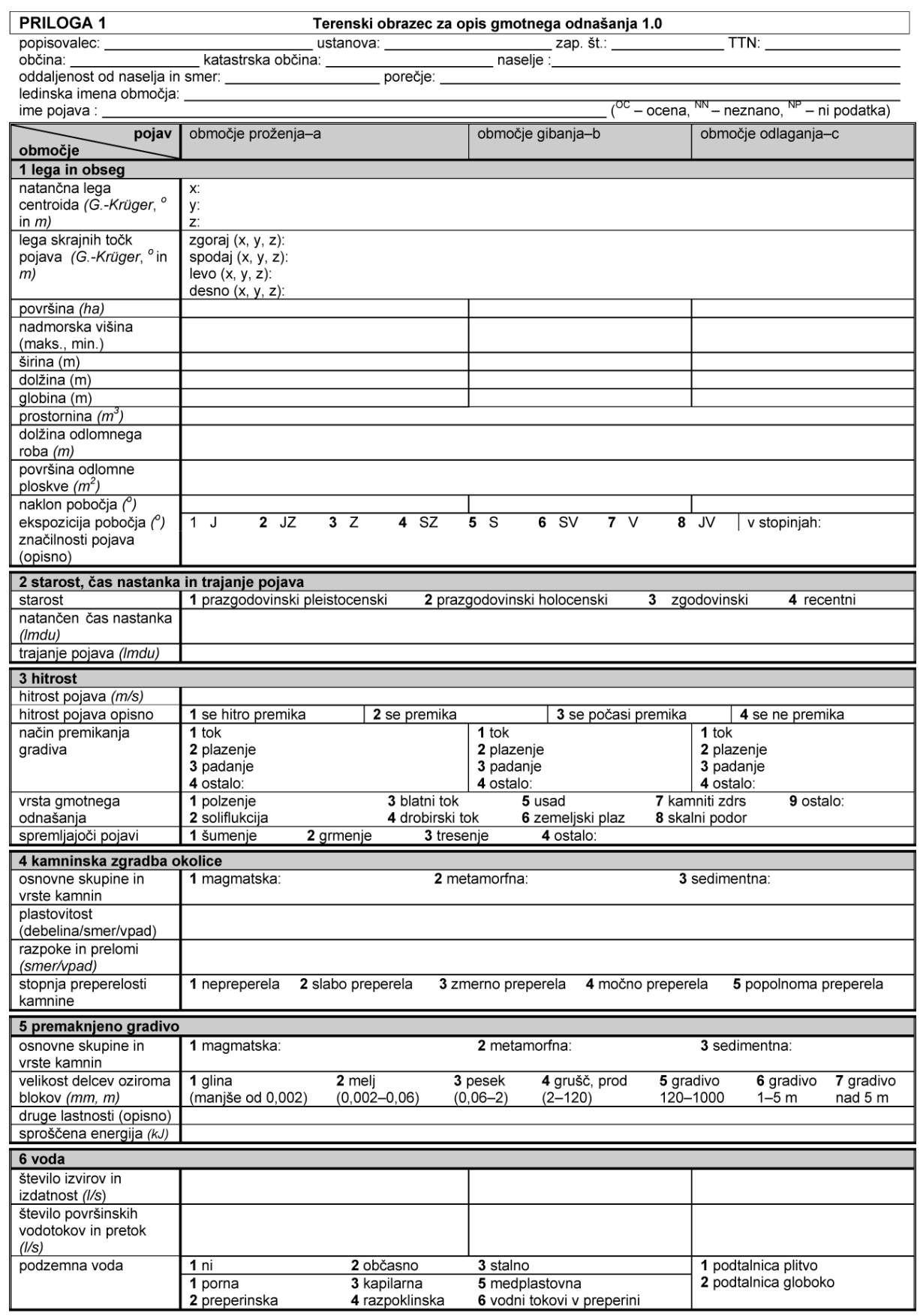




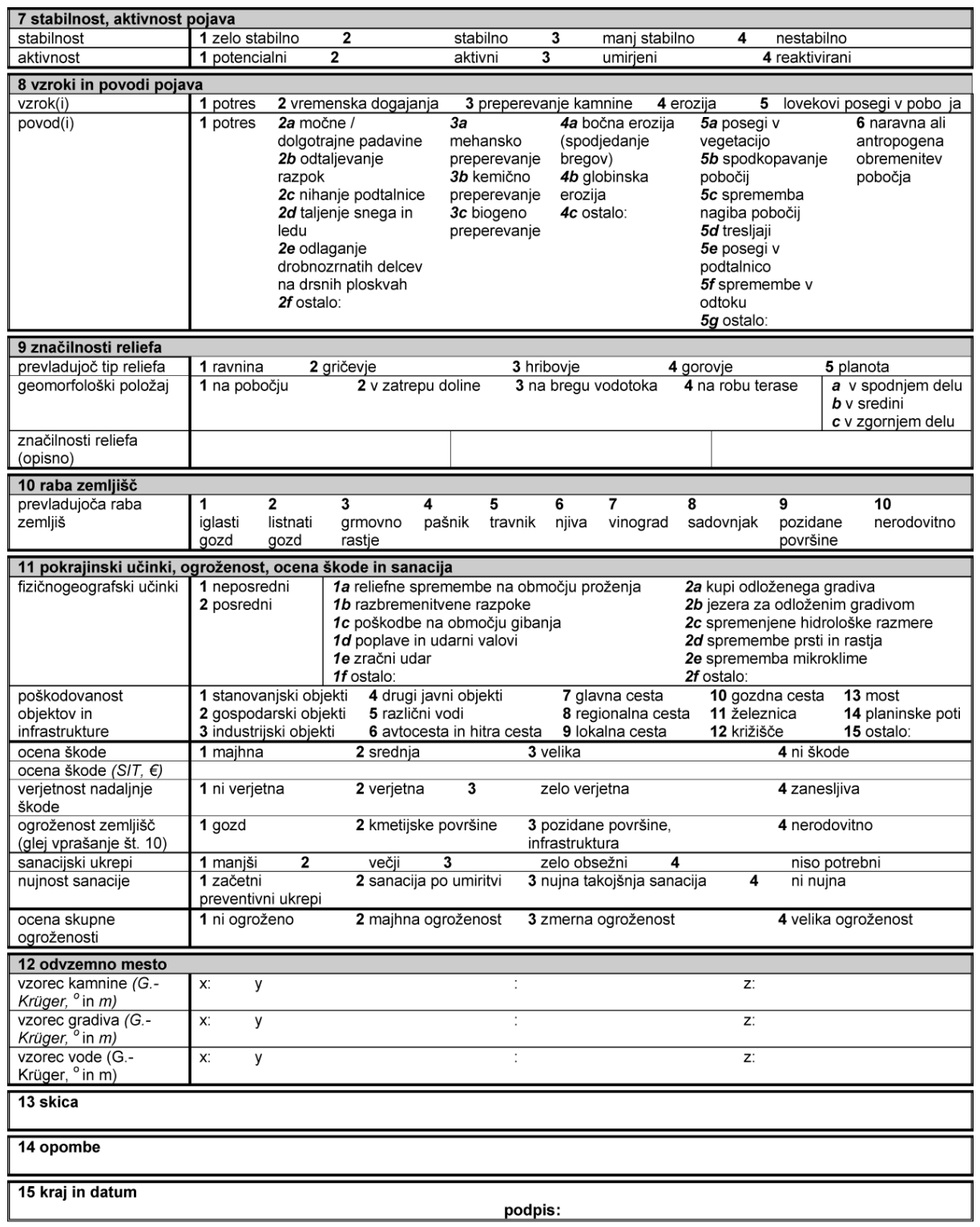

(c) Blaž Komac in Matija Zorn, Geografski inštitut Antona Melika ZRC SAZU, 2002 


\section{Priloga 2: Navodila za izpolnjevanje Terenskega obrazca za opis gmotnega odnašanja 1.0}

\section{Uvod}

Obrazec je namenjen preučevanju geomorfnih procesov na pobočjih. V tem primeru štejemo mednje glede na način premikanja gradiva tok (na primer drobirski tok), plazenje (na primer zemeljski plaz) in padanje (na primer podor). Za poimenovanje teh procesov se v tuji literaturi uporablja angleški izraz mass wasting, ki ga nekateri v slovenščino prevajajo kot "masovno odnašanje" (Mikoš 2000, 109). Zaradi pomensko spornega izraza "masovno" predlagamo ustreznejši izraz "gmotno odnašanje", ki pomeni odstranjevanje gmote $z$ delovanjem geomorfnih procesov na pobočjih. Izraz opisuje omenjene geomorfne procese na pobočjih, ne pa erozije in denudacije v ožjem smislu besed.

Navodila so nastala v želji po enotnem izpolnjevanju obrazca in razumevanju njegovih delov. V glavi preglednice so na levi strani nanizane lastnosti obravnavanih pobočnih procesov, $\mathrm{v}$ navpični smeri pa je preglednica razdeljena na tri stolpce, ki prikazujejo območje proženja (a), območje gibanja (b) in območje odlaganja (c). Kjer je vrstica $\mathrm{v}$ preglednici razdeljena na tri polja, ki so med seboj ločena $z$ navpično črto, podatke vpisujte za vsako območje posebej. Ob navedbi kategorije so v ležečem tisku in oklepaju vpisane tudi priporočene merske enote.

V glavo obrazca vpišite svoje ime in priimek, ustanovo, od koder prihajate, zaporedno številko obrazca, naslov in številko lista temeljnega topografskega načrta $\mathrm{v}$ merilu 1 : 5000 oziroma $1: 10.000$, na katerem je opisani pojav, občino, katastrsko občino v kateri je prišlo do pojava, najbližje naselje in smer ter oddaljenost od njega. Vpišite lego pojava v porečju tako, da najprej navedemo reko prvega reda, kraj dogodka pa nazadnje določimo z najbližjim vodotokom (na primer za plaz Stovžje, 15. 11. 2000: Soča, Koritnica, Predelica, Mangartski potok).

Vpišite ledinska imena na območju pobočnega procesa in v njegovi okolici. Vpišite ime pojava (na primer: "Macesnikov plaz"). Če ime ne obstaja, ga določite sami na podlagi toponimov oziroma posveta s prebivalci ali poznavalci območja.

Z oznako "OC" označite vnos ocen, če je podatek neznan vpišite "NN", če niste uspeli pridobiti podatka, v ustrezno polje vpišite "NP". Obrazec izpolnjujete tako, da v prazna polja vpišete ustrezen številčni podatek oziroma besedilo. Kjer so možni odgovori že našteti, obkrožite številko pred odgovorom oziroma vpišete dodatno besedilo v rubriko "ostalo". Če ni drugače navedeno, obkrožite vse odgovore, za katere mislite, da so ustrezni.

\section{Lega in obseg}

V prvo vrstico vpišite natančno lego centroida pojava z Gauss-Krügerjevimi koordinatami ali stopinjami. Nadmorsko višino navedete $\mathrm{v}$ metrih. $\mathrm{V}$ drugo vrstico na enak način vpišete lego skrajnih točk. Površino območja proženja, gibanja in odlaganja napišite v hektarih. Če posamezna območja med seboj niso jasno ločena, v prvo polje (a) vpišite le skupno površino in to navedite kot opombo v točki 14 . V naslednjo vrstico vpišite minimalno in maksimalno nadmorsko višino $v$ metrih za vsako območje posebej, in sicer tako, da je minimalna višina območja "a" enaka maksimalni višini območja "b" itd. V peto vrstico vpišite širino pojava za vsako območje posebej v metrih. Enako velja za opis dolžine pojava v šesti in njegove globine $v$ sedmi vrstici. Prostornino celotnega gradiva vpišite v osmo vrstico v kubičnih metrih. Predvsem pri podorih sta pomembna 
podatka dolžina odlomnega roba (deveta vrstica) v metrih in površina odlomne ploskve (deseta vrstica) v kvadratnih metrih. Naklon pobočja vpišite $v$ enajsto vrstico $v$ stopinjah za vsako območje posebej. Ekspozicijo pobočja v dvanajsti vrstici opišite $z$ izborom ustreznega polja (1-8) in po možnosti navedite natančno vrednost v stopinjah. $\mathrm{V}$ trinajsti vrstici opišite druge značilnosti pojava.

\section{Starost, čas nastanka in trajanje pojava}

V prvi vrstici z izborom polja ocenite starost pojava (1-4) (Zorn 2002b), v drugo pa vpišite natančen čas nastanka pojava, če je znan, v obliki leto-mesec-dan-ura (lmdu).

V tretjo vrstico vpišite čas trajanja pojava, če je znan.

\section{Hitrost}

V prvo vrstico vpišite hitrost pojava $v$ metrih na sekundo oziroma drugi enoti, če je potrebno $(\mathrm{cm} / \mathrm{s}, \mathrm{m} / \mathrm{h}, \mathrm{m} / \mathrm{dan}, \mathrm{m} / \mathrm{teden}, \mathrm{m} / \mathrm{mesec}$ in podobno). Če se med gibanjem gradiva spreminja vrsta pobočnega procesa, na primer iz zemeljskega plazu v drobirski tok, navedite hitrost za vsako vrsto pobočnega procesa posebej. Takšno navedbo omenite tudi v opombi (točka 14). V drugi vrstici z izborom polja (1-4) opišite hitrost pojava. $\mathrm{V}$ tretji vrstici z izborom polja (1-4) za vsako območje opišite način premikanja gradiva, v četrti pa $z$ izborom polja (1-9) opišite vrsto gmotnega odnašanja (Zorn in Komac 2002). V peto vrstico $\mathrm{z}$ izborom polja (1-4) opišite morebitne spremljajoče pojave. O slednjem se je priporočljivo pozanimati pri domačinih. Ob morebitnih slušnih spremljajočih pojavih med opombe (točka 14) vpišite oddaljenost priče dogodka od pobočnega procesa oziroma takratne vremenske in druge razmere, ki bi lahko vplivale na zaznavanje.

\section{Kamninska zgradba okolice}

V prvi vrstici z izborom polja (1-3) označite osnovno skupino kamnine v okolici pobočnega procesa (Verbič 1998, 74), nato pa za dvopičje vpišite natančno opredelitev vrste kamnine. Če je na območju več kamninskih vrst, med opombe vpišite njihovo stratigrafsko lego in narišite stratigrafski stolpec (točka 14). V drugo vrstico vpišite osnovne značilnosti plastovitosti, in sicer debelino plasti $v$ metrih ter smer in vpad kamninskih plasti v stopinjah. $V$ tretjo vrstico vpišite usmerjenost in vpad razpok in prelomov, oboje v stopinjah. V četrto vrstico z izborom ustreznega polja (1-5) opišite stopnjo preperelosti kamnine s pomočjo Schmidtovega kladiva ali opisno z razlago v opombah (točka 14).

Preglednica 2: Stopnja preperelosti kamnine (Chorley in ostali 1984, 197).

\begin{tabular}{|l|c|c|c|c|c|}
\hline Stopnja preperelosti kamnine & 1 & 2 & 3 & 4 & 5 \\
\hline $\mathrm{r}$ (vrednost testa s Schmidtovim kladivom) & 10 & 9 & 7 & 5 & 3 \\
\hline
\end{tabular}

\section{Premaknjeno gradivo}

V prvi vrstici z izborom polja (1-3) označite osnovno skupino kamnine, ki sestavlja premaknjeno gradivo (gmoto) (Verbič 1998, 74), nato pa za dvopičje vpišite natančno opredelitev vrste kamnine.

V drugi vrstici z izborom ustreznega polja opišete velikost premaknjenih delcev oziroma blokov $\mathrm{v}$ mm oziroma $\mathrm{v} \mathrm{m}$ pri podorih. Obkrožite lahko več polj, vendar jih $\mathrm{v}$ 
opombi rangirajte. $\mathrm{V}$ tretjo vrstico vpišite morebitne druge lastnosti kamnine. $\mathrm{V}$ četrto vrstico vpišite izračun sproščene energije po obrazcu $\mathrm{W}=\mathrm{V} \cdot \varphi \cdot \mathrm{g} \cdot \mathrm{h}$ oziroma $\mathrm{W}=\mathrm{mv}^{2} / 2$ $\left(\mathrm{g}=9,81 \mathrm{~m} / \mathrm{s}^{2}\right)$ (Zorn 2001, 100). V preglednici 4 navajamo okvirne vrednosti specifične teže nekaterih kamnin. Natančne vrednosti za posamezno kamnino preverite v geološki literaturi.

Preglednica 3: Specifična teža nekaterih snovi (Waltham 1994, 48; Mirtič in ostali 1999).

\begin{tabular}{|l|c|}
\hline Snov & $\begin{array}{l}\text { specifična } \\
\text { teža }\left(\mathrm{kg} / \mathrm{m}^{3}\right)\end{array}$ \\
\hline Voda & 1000 \\
\hline Glina & 1800 \\
\hline muljevec (glinavec in meljevec) & 2300 \\
\hline skrilavec (metamorfni) & 2300 \\
\hline Peščenjak & $1900-2600$ \\
\hline Apnenec & $2600-2700$ \\
\hline Granodiorit & 2690 \\
\hline Granit & 2700 \\
\hline Gabro & 3000 \\
\hline
\end{tabular}

\section{Voda}

V prvo vrstico vnesite število in izdatnost izvirov v litrih na sekundo za vsako območje posebej. Po območjih $(\mathrm{a}, \mathrm{b}, \mathrm{c})$ vpišite število in pretok površinskih vodotokov $\mathrm{v}$ drugi vrstici. V tretji vrstici $z$ izborom ustreznega polja (1-3) označite pojav podzemne vode, $\mathrm{v}$ četrti vrstici z izborom ustreznega polja (1-6) opišite prevladujočo ter za proces odločilno vrsto podzemne vode (porna, preperinska, kapilarna, razpoklinska, medplastovna, vodni tokovi $v$ preperini) in nazadnje še $z$ izborom ustreznega polja (1-2) opredelite globino podtalnice (Ribičič 2002).

\section{Stabilnost in aktivnost pojava}

V prvo vrstico z izborom ustreznega polja (1-4) opišite stabilnost pobočnega procesa, $\mathrm{V}$ drugo vrstico pa, ravno tako z izborom ustreznega polja (1-4), njegovo aktivnost.

\section{Vzroki in povodi pojava}

V prvi vrstici z izborom ustreznega polja (1-5) opišite poglavitni vzrok, v drugi (1-6) pa poglavitni povod pobočnega procesa (Zorn in Komac 2002).

\section{Značilnosti reliefa}

V prvi vrstici z izborom ustreznega polja (1-5) opišite prevladujoč tip reliefa, $v$ drugi vrstici pa opišite geomorfološki položaj glede na lego v porečju (1-4) in glede na višinsko razporeditev $(a-c)$. V tretji vrstici značilnosti reliefa po območjih $(a, b, c)$ opišite $z$ lastnimi besedami.

\section{Raba zemljišč}

V prvo vrstico z izborom ustreznega polja (1-10) vpišite prevladujočo rabo zemljišč. 
11 Pokrajinski učinki, ogroženost, ocena škode in sanacija

$\mathrm{V}$ prvo vrstico $\mathrm{z}$ izborom ustreznega polja (1-2 in 1a-1f, 2a-2f) opišite fizičnogeografske učinke pojava, $v$ drugo pa poškodovanost objektov in infrastrukture $(1-15)$. V tretji vrstici z izborom ustreznega polja (1-4) ocenite morebitno škodo, $v$ četrti vrstici pa navedite oceno vrednosti škode $v$ slovenskih tolarjih (SIT) oziroma evrih $(€)$. V peti vrstici z izborom ustreznega polja (1-4) ocenite verjetnost nadaljnje škode, v šesti opredelite ogroženost zemljišč (1-4). V sedmi vrstici navedite obseg sanacijskih ukrepov (1-4). Manjše sanacijske ukrepe zmore posameznik (1), večje (2) lokalna skupnost, pri zelo obsežnih sanacijskih ukrepih pa je potrebno posredovanje države (3). $\mathrm{V}$ osmi vrstici ocenite nujnost sanacije $(1-4)$. V deveti vrstici prav tako z izborom ustreznega polja ocenite skupno ogroženost (1-4) (Pečnik 2002, 63-73; Ribičič 2002).

\section{Odvzemno mesto}

$\mathrm{V}$ ta del preglednice vpišite koordinate oziroma čim natančnejšo lego mesta odvzema vzorca kamnine (prva vrstica), gradiva, ki je bilo premaknjeno s pobočnim procesom (druga vrstica) ali vode (tretja vrstica). Podatke vpišite v obliki Gauss-Krügerjevih koordinat ali stopinj, nadmorsko višino vpišite v metrih.

\section{Skica}

Skico narišemo na terenu. Prikazuje naj osnovne značilnosti pojava, pomembnejše izmerjene vrednosti (naklon, razdalja, lega, odvzemno mesto vzorca). Skica je dopolnitev fotografskemu in drugemu gradivu, zato na njej poudarimo bistvene značilnosti pojava. $\mathrm{Ob}$ glavni skici je priporočljivo narisati stratigrafski stolpec, skico poteka razpok in prelomov oziroma plastovitosti ter druge značilnosti kamnin, reliefa in podobno. Priporočljivo je narisati geomorfološko karto širše okolice, s pomočjo katere sklepamo na starejše pobočne procese.

\section{Opombe}

V to polje vpišite vaše opombe, opažanja in razmišljanja. Opombe dopolnite z izjavami očividcev in navedite pregledano strokovno literaturo. Vpišite krajevna in ledinska imena, ki kažejo na pobočne procese, kot sta na primer imeni Podertje in Na plazu (Zorn 2001, 109). Navedite pripovedke, legende ali pesmi, na podlagi katerih lahko sklepamo na pobočne procese v preteklosti (na primer: Simon Gregorčič, Rabeljsko jezero, 1947). V opombah opišite vremenske razmere v času obiska (padavine, snežna odeja, oblačnost, megla) in vidljivost v metrih.

\section{$15 \mathrm{Kraj}$, datum in podpis}

Vpišite kraj in datum izpolnjevanja obrazca ter se podpišite.

(C) Blaž Komac in Matija Zorn, Geografski inštitut Antona Melika ZRC SAZU, 2002 